Proyecciones Journal of Mathematics

Vol. 41, $\mathrm{N}^{o}$ 1, pp. 111-135, February 2022.

Universidad Católica del Norte

Antofagasta - Chile

\title{
An existence result for a strongly nonlinear parabolic equations with variable nonlinearity
}

\author{
Mustapha Ait Hammou \\ Sidi Mohamed Ben Abdellah University, Morocco \\ Elhoussine Azroul \\ Sidi Mohamed Ben Abdellah University, Morocco \\ Badr Lahmi \\ Moulay Ismail University, Morocco \\ Received : September 2020. Accepted : July 2021
}

\begin{abstract}
We prove the existence of a solution for the strongly nonlinear parabolic initial boundary value problem associated to the equation

$$
u_{t}-\operatorname{div} a(x, t, \nabla u)+g(x, t, u, \nabla u)=f,
$$

where the vector field $a(x, t, \xi)$ exhibits non-standard growth conditions.
\end{abstract}

Key words: Strongly nonlinear parabolic equations, Variable exponents, Weak solution, Existence.

MSC (2010): 35K55, 46E35, 35D30. 


\section{Introduction}

Let $\Omega$ be a bounded domain in $\mathbf{R}^{N}, N \geq 2$, with a Lipschitz boundary denoted by $\partial \Omega$. Fixing a final time $T>0$, we denote by $Q$ the cylinder $\Omega \times] 0, T[$ and $\Gamma=\partial \Omega \times] 0, T[$ its lateral surface. We consider the following strongly nonlinear parabolic initial-boundary problem :

$$
\begin{cases}\frac{\partial u}{\partial t}-\operatorname{div} a(x, t, \nabla u)+g(x, t, u, \nabla u)=f & \text { in } Q \\ u(x, t)=0 & \text { in } \Gamma \\ u(x, 0)=u_{0}(x) & \text { in } \Omega\end{cases}
$$

The function $a$ satisfying the Leray-Lions-like conditions with respect to the variable exponent $p(\cdot): \bar{\Omega} \rightarrow[1,+\infty[$ which is a Log-Hölder continuous function only dependent on the space variable $x$ (see definitions below). The nonlinear term $g(x, t, s, \xi)$ satisfies the more general natural growth condition with respect to $\nabla u$

$$
|g(x, t, u, \nabla u)| \leq b(|u|)\left(\theta(x, t)+|\nabla u|^{p(x)}\right),
$$

for some continuous function $b: \mathbf{R}^{+} \rightarrow \mathbf{R}^{+}$and the sign condition

$$
g(x, t, u, \nabla u) u \geq 0 .
$$

$u_{0}$ lies in $L^{2}(\Omega)$ and the right-hand side $f$ is assumed to belong to $X^{\prime}$ where the space $X$, as introduced and discussed in [3] (see also [19]), is given by

$$
X:=\left\{u \in L^{p^{-}}\left(0, T ; W_{0}^{1, p(\cdot)}(\Omega)\right):|\nabla u| \in L^{p(\cdot)}(Q)\right\},
$$

Given the assumptions we have made, we think that this space is a reasonable framework to discuss our problem.

The specific attention accorded to problems with variable exponent is due to their applications in mathematical physics. Precisely, such equations are used to model phenomenon which arise in electrorheological fluids (see [15]) as well as in some model of image processing (see [5]) and elasticity ([21]).

For the problem (1.1) with $g \equiv 0$ having $p(x, t)$ - structure, the authors proved in [6] and independently in [18] the existence of a least a weak solution. Besides, Fu and Pan in [9] have proved an existence result of weak solutions for the problem

$$
\begin{cases}\frac{\partial u}{\partial t}-\operatorname{div} a(x, t, u, \nabla u)+a_{0}(x, t, u, \nabla u)=f & \text { in } Q=\Omega \times] 0, T[ \\ u(x, t)=0 & \text { in } \Gamma=\partial \Omega \times] 0, T[ \\ u(x, 0)=u_{0}(x) & \text { in } \Omega\end{cases}
$$


where $u_{0} \in L^{2}(\Omega)$ and $f \in W^{-1, x} L^{p^{\prime}(x)}(Q)$ under some $p(x)$-growth conditions.

In this work, we prove the existence of solutions for nonlinear parabolic initial boundary value problems associated to equations whose prototype is:

$$
\left.\frac{\partial u}{\partial t}-\operatorname{div}\left(|\nabla u|^{p(x)-2} \nabla u\right)+u|\nabla u|^{p(x)}=f \text { in } Q:=\Omega \times\right] 0, T[.
$$

We are mainly concerned with the existence of weak solutions for the strongly nonlinear problem (1.1) in the variational framework where $p(\cdot)$ is only dependent on the space variable, $-\operatorname{div} a(x, t, \nabla u)$ is a Leray-Lions type operator which growths like $|\nabla u|^{p(x)-1}$ not depending on $u$ and where the perturbation $g$ has a critical growth with respect to $\nabla u$. For this, we will use a Galerkin approximation to construct solutions. Then we want to conclude from a energy estimate and by using the sign condition on $g$ that the approximated solution is uniformly bounded in $X$. We apply the timeregularizing convolution operator to prove the all everywhere convergence of the gradient of approximate solution to the gradient of the limit, which is important in the limiting process. Finally, we will see that the solutions of the approximate solution converge to the solution of the model problem in $C\left([0, T], L^{2}(\Omega)\right)$ which gives meaning to the initial condition.

\section{Preliminaries}

Let

$$
p^{-}:=\operatorname{ess} \inf _{x \in \Omega} p(x) \text { and } p^{+}:=\operatorname{ess} \sup _{x \in \Omega} p(x) .
$$

We will make use of the following assumption

$$
1<p^{-} \leq p(x) \leq p^{+}<+\infty .
$$

An interesting feature of generalized variable exponent Sobolev space is that smooth functions are not dense in it without additional assumptions on the exponent $p(\cdot)$. However, when the exponent satisfies the following so-called log-Hölder condition

$$
\exists C>0: \quad|p(x)-p(y)| \log \left(e+\frac{1}{|x-y|}\right) \leq C, \quad \text { for all } x, y \in \bar{\Omega},
$$

then $C_{0}^{\infty}(\bar{\Omega})$ is dense in $L^{p(\cdot)}(\Omega)$ (see $[8,16,20]$ ) and we have the Poincaré inequality (see [7, Theorem 8.2.4], [8, Theorem 2.7] and [10, Theorem 4.3]): 
Lemma 2.1. Let $\Omega$ be a bounded domain in $\mathbf{R}^{N}$. If $p \in C(\bar{\Omega})$ satisfy (2.1) and (2.2), then there exists a constant $C>0$ depending only on $\Omega$ and the function $p$ such that

$$
\|u\|_{L^{p(\cdot)}(\Omega)} \leq C\|\nabla u\|_{L^{p(\cdot)(\Omega)}} \quad \text { for all } u \in W_{0}^{1, p(\cdot)}(\Omega) .
$$

In particular, the space $W_{0}^{1, p(\cdot)}(\Omega)$ has a norm $\|\cdot\|_{W_{0}^{1, p(\cdot)}(\Omega)}$ given by

$$
\|u\|_{W_{0}^{1, p(\cdot)}(\Omega)}=\|\nabla u\|_{L^{p(\cdot)}(\Omega)} \quad \text { for all } u \in W_{0}^{1, p(\cdot)}(\Omega),
$$

which equivalent to $\|\cdot\|_{W^{1, p(\cdot)}(\Omega)}$. Moreover, the embedding $W_{0}^{1, p(\cdot)}(\Omega) \hookrightarrow L^{p(\cdot)}(\Omega)$ is compact (see $[11]$ ).

As in [13] (lemma 1.3. p.12) we can prove the following lemma

Lemma 2.2. Suppose that $1 \leq p(x)<\infty$. Let $\left\{v_{n}\right\}_{n}$ be bounded in $L^{p(\cdot)}(\Omega)$. If $v_{n} \rightarrow v$ a.e. in $\Omega$, then $v_{n} \rightarrow v$ weakly in $L^{p(\cdot)}(\Omega)$.

We extend a variable exponent function $p: \bar{\Omega} \rightarrow[1,+\infty[$ to $\bar{Q} \rightarrow$ $[1,+\infty[$ by setting $p(x, t)=p(x)$ for all $(x, t) \in \bar{Q}$.

\section{The space $X$}

As in [3], we consider the following functional space

$$
X:=\left\{u \in L^{p^{-}}\left(0, T ; W_{0}^{1, p(\cdot)}(\Omega)\right):|\nabla u| \in L^{p(\cdot)}(Q)\right\},
$$

which is a separable and reflexive Banach space endowed with the norm

$$
|u|_{X}:=\|u\|_{L^{p^{-}}\left(0, T ; W_{0}^{1, p(\cdot)}(\Omega)\right)}+\|\nabla u\|_{L^{p(\cdot)}(Q)}
$$

or the equivalent norm

$$
\|u\|_{X}:=\|\nabla u\|_{L^{p(\cdot)}(Q)} .
$$

Lemma 3.1. Assume that (2.1) and (2.2) are fulfilled. If $0<|\Omega|<+\infty$, the Banach space $X$ is continuously embedded in $L^{1}(Q)$. Moreover, there is a constant $c_{0}>0$ such that for every $u \in X$, one has $\|u\|_{L^{1}(Q)} \leq c_{0}|u|_{X}$. 
Proof. Let $u \in X$. Using the Hölder inequality one has

$$
\int_{\Omega}|u(t)| d x \leq\left(1+\frac{1}{p^{-}}-\frac{1}{p^{+}}\right) \max \left(|\Omega|^{\frac{1}{p^{\prime-}}},|\Omega|^{\frac{1}{p^{+}}}\right)\|u(t)\|_{L^{p(\cdot)}(\Omega)} .
$$

By Lemma 2.1, there is a constant $C>0$ such that

$$
\int_{\Omega}|u(t)| d x \leq C\left(1+\frac{1}{p^{-}}-\frac{1}{p^{+}}\right) \max \left(|\Omega|^{\frac{1}{p^{\prime-}}},|\Omega|^{\frac{1}{p^{\prime+}}}\right)\|\nabla u(t)\|_{L^{p(\cdot)}(\Omega)} .
$$

Integrating between 0 and $T$ and using the Hölder inequality, we get

$\int_{Q}|u(t)| d x \leq C\left(1+\frac{1}{p^{-}}-\frac{1}{p^{+}}\right) \max \left(|\Omega|^{\frac{1}{p^{\prime-}}},|\Omega|^{\frac{1}{p^{\prime+}}}\right) T^{1-\frac{1}{p^{-}}}\left(\int_{0}^{T}\|\nabla u(t)\|_{L^{p(\cdot)}(\Omega)}^{p^{-}}\right)^{\frac{1}{p^{-}}}$,

which yields

$$
\int_{Q}|u(t)| d x \leq C\left(1+\frac{1}{p^{-}}-\frac{1}{p^{+}}\right) \max \left(|\Omega|^{\frac{1}{p^{\prime}}},|\Omega|^{\frac{1}{p^{\prime+}}}\right) T^{1-\frac{1}{p^{-}}}|u|_{X} .
$$

Remark 3.2. $\left[3\right.$, Lemma 3.1] $\mathcal{C}_{0}^{\infty}(Q)$ is dense in $X$. Moreover we have the following continuous dense embedding

$$
L^{p^{+}}\left(0, T ; W_{0}^{1, p(\cdot)}(\Omega)\right) \hookrightarrow_{d} X \hookrightarrow_{d} L^{p^{-}}\left(0, T ; W_{0}^{1, p(\cdot)}(\Omega)\right) .
$$

For the corresponding dual spaces, we have

$$
L^{\left(p^{-}\right)^{\prime}}\left(0, T ; W^{-1, p^{\prime}(\cdot)}(\Omega)\right) \hookrightarrow X^{\prime} \hookrightarrow L^{\left(p^{+}\right)^{\prime}}\left(0, T ; W_{0}^{-1, p^{\prime}(\cdot)}(\Omega)\right) .
$$

Lemma 3.3. Let $Y$ be a Banach space such that the embedding $L^{1}(\Omega) \hookrightarrow$ $Y$ is continuous. If $\mathcal{F}$ is bounded in $X$ and relatively compact in $L^{1}(0, T ; Y)$ then $\mathcal{F}$ is relatively compact in $L^{1}(Q)$.

Proof. Let $\epsilon>0$. Since the embedding $W_{0}^{1, p(\cdot)}(\Omega) \hookrightarrow L^{1}(\Omega)$ is compact, by [17, Lemma 8] there exists a finite constant $N>0$ such that for every $v \in W_{0}^{1, p(\cdot)}(\Omega)$ one has

$$
\|v\|_{L^{1}(Q)} \leq \epsilon \int_{0}^{T}\|v\|_{W_{0}^{1, p(\cdot)}(\Omega)} d t+N\|v\|_{L^{1}(0, T ; Y)} .
$$


Being $\mathcal{F}$ relatively compact, for $\epsilon$, there is a finite sequence $u_{1}, u_{2}, \ldots, u_{m}$ in $\mathcal{F}$ satisfying

$$
\forall u \in \mathcal{F}, \exists u_{n}, 1 \leq n \leq m, \text { such that }\left\|u_{n}-u\right\|_{L^{1}(0, T ; Y)} \leq \epsilon
$$

Hence, we get

$$
\left\|u_{n}-u\right\|_{L^{1}(Q)} \leq \epsilon \int_{0}^{T}\left\|u_{n}-u\right\|_{W_{0}^{1, p(\cdot)}(\Omega)} d t+N\left\|u_{n}-u\right\|_{L^{1}(0, T ; Y)} .
$$

By the fact that $\int_{0}^{T}\left\|u_{n}-u\right\|_{W_{0}^{1, p(\cdot)}(\Omega)} d t$ is bounded, as a consequence of the continuous embedding $X \hookrightarrow L^{1}\left(0, T ; W_{0}^{1, p(\cdot)}(\Omega)\right)$, we conclude that $\mathcal{F}$ is relatively compact in $L^{1}(Q)$.

Lemma 3.4. Let $\left(u_{n}\right)$ be a sequence of elements of $X$ such that

$$
u_{n} \rightarrow u \text { weakly in } X
$$

and

$$
\frac{\partial u_{n}}{\partial t}=h_{n}+k_{n} \operatorname{in} \mathcal{D}^{\prime}(Q),
$$

where $\left(h_{n}\right)$ is a bounded sequence in $X^{\prime}$ and $\left(k_{n}\right)$ is a bounded sequence in $L^{1}(Q)$. Then

$$
u \in \mathcal{C}\left(0, T ; W^{-1,1}(\Omega)\right) \text { and } u_{n} \rightarrow u \text { strongly in } L^{1}(Q) .
$$

Proof. Observe that the sequence $\left(u_{n}\right)$ is bounded in $X$ and in $L^{1}\left(0, T ; W^{-1,1}(\Omega)\right)$ as well, since the embedding $L^{1}(\Omega) \hookrightarrow W^{-1,1}(\Omega)$ is continuous, by Remark 3.2 we conclude that the following embedding are continuous

$$
X \hookrightarrow L^{1}\left(0, T ; W_{0}^{1, p(\cdot)}(\Omega)\right) \hookrightarrow L^{1}\left(0, T ; L^{1}(\Omega)\right) \hookrightarrow L^{1}\left(0, T ; W^{-1,1}(\Omega)\right) .
$$

On the other hand, $\frac{\partial u_{n}}{\partial t}$ is bounded in $X^{\prime}+L^{1}(Q)$ and in $L^{1}\left(0, T ; W^{-1,1}(\Omega)\right)$ too, since

$X^{\prime}+L^{1}(Q) \hookrightarrow L^{1}\left(0, T ; W^{-1,1}(\Omega)\right)+L^{1}\left(0, T ; L^{1}(\Omega)\right) \hookrightarrow L^{1}\left(0, T ; W^{-1,1}(\Omega)\right)$

with continuous imbedding. Thus, by [17, Lemma 4] one has

$$
u_{n} \in \mathcal{C}\left(0, T ; W^{-1,1}(\Omega)\right) \text { and }\left\|\tau_{h} u_{n}-u_{n}\right\|_{L^{1}\left(0, T-h ; W^{-1,1}(\Omega)\right)} \rightarrow 0 \text { as } h \rightarrow 0,
$$


for all $n \in \mathbf{N}$. Let $0<t_{1}<t_{2}<T$. By the Jensen inequality, there exists a constant $c_{T}$ which depends on $T$ and $p^{-}$such that

$$
\left\|\int_{t_{1}}^{t_{2}} u_{n}(t) d t\right\|_{W_{0}^{1, p(\cdot)}(\Omega)}^{p^{-}} \leq c_{T} \int_{t_{1}}^{t_{2}}\left\|u_{n}(t)\right\|_{W_{0}^{1, p(\cdot)}(\Omega)}^{p^{-}} d t \leq c_{T}\left|u_{n}\right|_{X}^{p^{-}}
$$

By virtue of the compact embedding $W_{0}^{1, p(\cdot)}(\Omega) \hookrightarrow \hookrightarrow L^{1}(\Omega)$, we deduce that $\left(\int_{t_{1}}^{t_{2}} u_{n}(t) d t\right)_{n}$ is relatively compact in $L^{1}(\Omega)$ and also in $W^{-1,1}(\Omega)$. Applying [17, Theorem 1], we conclude that $\left(u_{n}\right)$ is relatively compact in $L^{1}\left(0, T ; W^{-1,1}(\Omega)\right)$. Since the imbedding $L^{1}(\Omega) \hookrightarrow W^{-1,1}(\Omega)$ is continuous, by Lemma 3.3, we get $\left(u_{n}\right)$ is relatively compact in $L^{1}(Q)$. Therefore, up to a subsequence,

$$
u_{n} \rightarrow u \text { strongly in } L^{1}(Q) \text { and a.e. in } Q .
$$

Moreover, $u \in \mathcal{C}\left(0, T ; W^{-1,1}(\Omega)\right)$.

As in [18] we can proof the following lemma

Lemma 3.5. Assume that (2.2) holds true. If $u \in X \cap L^{2}(Q)$ with $\frac{\partial u}{\partial t} \in X^{\prime}+L^{1}(Q)$, then there exists a sequence $\left\{u_{i}\right\}$ in $\mathcal{C}_{0}^{\infty}(\bar{Q})$ such that

$$
\begin{aligned}
u_{i} & \rightarrow u \text { strongly in } X \cap L^{2}(Q) \text { and } \\
\frac{\partial u_{i}}{\partial t} & \rightarrow \frac{\partial u}{\partial t} \text { in } X^{\prime}+L^{1}(Q) .
\end{aligned}
$$

We will use the following results which can be proved as in [2].

Lemma 3.6. (Integration by parts.) Assume that $p(\cdot)$ satisfies (2.2). Let $u, v \in X$ such that $u_{t}, v_{t} \in X^{\prime}$. Then, for almost every $t_{1}, t_{2} \in[0, T]$ one has

$$
\int_{t_{1}}^{t_{2}} \int_{\Omega} u v_{t} d x d t+\int_{t_{1}}^{t_{2}} \int_{\Omega} u_{t} v d x d t=\left[\int_{\Omega} u(t) v(t) d x\right]_{t_{1}}^{t_{2}}
$$

\section{Basic assumptions and the main result}

We assume that $a(x, t, \xi): Q \times \mathbf{R}^{N} \rightarrow \mathbf{R}^{N}$ is a Carathéodory function (i.e. continuous with respect to $\xi \in \mathbf{R}^{N}$ for a.e. $(x, t) \in Q$ and measurable with respect to $(x, t) \in Q$ for all $\left.\xi \in \mathbf{R}^{N}\right)$ which satisfies, for a.e. $(x, t) \in Q$, for every $\xi, \xi^{\prime} \in \mathbf{R}^{N}$ with $\xi \neq \xi^{\prime}$, and some $C(x, t) \in L^{p^{\prime}(\cdot)}(Q)$ the following assumptions: 


$$
\begin{gathered}
|a(x, t, \xi)| \leq\left(C(x, t)+|\xi|^{p(x)-1}\right) \\
\left(a(x, t, \xi)-a\left(x, t, \xi^{\prime}\right)\right) \cdot\left(\xi-\xi^{\prime}\right)>0, \\
a(x, t, \xi) \cdot \xi \geq|\xi|^{p(x)} .
\end{gathered}
$$

$g: Q \times \mathbf{R} \times \mathbf{R}^{N} \rightarrow \mathbf{R}$ is a Carathéodory function such that for a.e. $(x, t) \in Q$ and all $(s, \xi) \in \mathbf{R} \times \mathbf{R}^{N}$ with $\theta \in L^{1}(Q)$ and some continuous function $b: \mathbf{R}^{+} \rightarrow \mathbf{R}^{+}$:

$$
\begin{gathered}
|g(x, t, s, \xi)| \leq b(|s|)\left(\theta(x, t)+|\xi|^{p(x)}\right), \\
g(x, t, s, \xi) s \geq 0
\end{gathered}
$$

In what follows $T_{k}(k>0)$ denotes the truncation function defined on $\mathbf{R}$ by $T_{k}(s)=\max (-k, \min (k, s))$. Our main result is the following existence theorem:

Theorem 4.1. Let $f \in X^{\prime}$ and $u_{0} \in L^{2}(\Omega)$. Assume that (4.1)-(4.5) hold true. Then there exists at least one weak solution $u$ of problem (1.1) in the following sense: $g(., ., u, \nabla u) \in L^{1}(Q), g(., ., u, \nabla u) u \in L^{1}(Q)$ and

$$
\begin{aligned}
& -\int_{Q} u \varphi_{t} d x d t+\int_{Q} a(x, t, \nabla u) \nabla \varphi d x d t+\int_{Q} g(x, t, u, \nabla u) \varphi d x d t \\
& =\langle f, \varphi\rangle+\int_{\Omega} u_{0}(x) \varphi(x, 0) d x
\end{aligned}
$$

for all $\varphi \in X \cap L^{\infty}(Q) \cap C^{1}\left([0, T] ; L^{2}(\Omega)\right)$ with $\varphi(\cdot, t)=0$ in a neighborhood of $T$.

\section{Proof of the main result}

\section{STEP I. Galerkin solutions.}

We choose a sequence of functions $\left\{\omega_{i}\right\}_{i=1}^{\infty} \subset \mathcal{C}_{0}^{\infty}(\Omega)$ orthonormal with respect to the Hilbert space $L^{2}(\Omega)$ such that $\bigcup_{k=1}^{\infty} V_{k}$, where we denote $V_{k}=\operatorname{span}\left\{\omega_{1}, \ldots, \omega_{k}\right\}$, is dense in $H_{0}^{s}(\Omega)$ with $s$ large enough such as 
$s>\frac{N}{2}+1$ so that $H_{0}^{s}(\Omega)$ is continuously embedded in $\mathcal{C}^{1}(\bar{\Omega})$, (see [14]).

Let

$$
X_{k}=\left\{v(x, t): v=\sum_{i=1}^{k} d_{i}(t) \omega_{i}(x), d_{i}(t) \in \mathcal{C}^{1}([0, T])\right\} .
$$

It's easy to see that $\mathcal{C}_{0}^{\infty}(Q) \subset \overline{\bigcup_{k=1}^{\infty} X_{k}}$ with respect to the norm

$$
\|v\|_{\mathcal{C}_{0}^{1,0}(Q)}=\sup _{(x, t) \in Q}\{|v(x, t)|,|\nabla v(x, t)|\} .
$$

Since $\mathcal{C}_{0}^{\infty}(Q)$ is dense in $L^{p^{+}}\left(0, T ; W_{0}^{1, p(\cdot)}(\Omega)\right)$, one has $\bigcup_{k=1}^{\infty} X_{k}$ is dense in the space $L^{p^{+}}\left(0, T ; W_{0}^{1, p(\cdot)}(\Omega)\right)$. Then, according to Remark 3.2 we get that $\bigcup_{k=1}^{\infty} X_{k}$ is dense in $X$.

For every $f \in X^{\prime}$, there is a sequence $\left\{f_{n}\right\}_{n} \subset \bigcup_{k=1}^{\infty} X_{k}$ such that $f_{n} \rightarrow f$ strongly in $X^{\prime}$. Indeed, let $\varepsilon>0$ be arbitrary. $f$ can be represented as $f=-\operatorname{div} F$, where $F=\left(f_{1}, f_{2}, \ldots, f_{N}\right) \in\left(L^{p^{\prime}(\cdot)}(Q)\right)^{N}$. Since $\mathcal{C}_{0}^{\infty}(Q)$ is dense in $L^{p^{\prime}(\cdot)}(Q)$, for every $i \in\{1,2, \ldots, N\}$ there is $\theta_{i} \in \mathcal{C}_{0}^{\infty}(Q)$ such that $\left\|f_{i}-\theta_{i}\right\|_{L^{p^{\prime}(\cdot)(Q)}} \leq \frac{\varepsilon}{2 N}$. Setting $\theta=-\operatorname{div} \Theta$ with $\Theta=\left(\theta_{1}, \theta_{2}, \ldots, \theta_{N}\right)$, one has $\theta \in \mathcal{C}_{0}^{\infty}(Q)$. By the fact that $\mathcal{C}_{0}^{\infty}(Q) \subset \overline{\bigcup_{n=1}^{\infty} X_{n}}$, there exists $h \in \bigcup_{n=1}^{\infty} X_{n}$ such that $\|\theta-h\|_{\infty, Q} \leq \frac{\varepsilon}{2 c_{0}}, c_{0}$ being the constant in Lemma 3.1. Therefore,

$$
\begin{aligned}
\|f-h\|_{X^{\prime}} & =\sup _{v \in X,|v|_{X} \leq 1}|\langle f-h, v\rangle| \\
& \leq \sum_{i=1}^{N}\left\|f_{i}-\theta_{i}\right\|_{L^{p^{\prime}(x)}(Q)}+\|\theta-h\|_{\infty, Q} \sup _{v \in X,|v|_{X} \leq 1}\|v\|_{L^{1}(Q)} \leq \varepsilon .
\end{aligned}
$$

We also note that there exists a sequence $u_{0_{n}} \subset \bigcup_{i=1}^{\infty} V_{n}$ such that $u_{0_{n}} \rightarrow u_{0}$ in $L^{2}(\Omega)$.

Definition 5.1. A function $u_{n} \in X_{n}$ is called Galerkin solution of (1.1) if and only if

$$
\int_{\Omega} \frac{\partial u_{n}}{\partial t} v d x+\int_{\Omega} a\left(x, t, \nabla u_{n}\right) \cdot \nabla v d x+\int_{\Omega} g\left(x, t, u, \nabla u_{n}\right) v d x=\int_{\Omega} f_{n}(t) v d x
$$

for all $v \in V_{n}$ and all $t \in[0, T]$ with $u_{n}(x, 0)=u_{0_{n}}(x)$.

Setting $u_{n}(x, t)=\sum_{i=1}^{n} d_{i}(t) \omega_{i}(x)$, we then try to look for the coefficients $d_{i}$. To do this, we define a vector valued function $y_{n}(t, d):[0, T] \times \mathbf{R}^{n} \rightarrow \mathbf{R}^{n}$ 
for $d=\left(d_{1}, \ldots, d_{n}\right)$ by

$$
\begin{aligned}
\left(y_{n}(t, d)\right)_{i} & =\int_{\Omega} a\left(x, t, \sum_{i=1}^{n} d_{n i}(t) \nabla \omega_{i}(x)\right) \cdot \nabla \omega_{i}(x) d x \\
& +\int_{\Omega} g\left(x, t, \sum_{i=1}^{n} d_{n i}(t) \omega_{i}(x), \sum_{i=1}^{n} d_{n i}(t) \nabla \omega_{i}(x)\right) \omega_{i}(x) d x
\end{aligned}
$$

for $i=1, \ldots, n$.

Note that the function $y_{n}(t, d)$ is continuous because $a$ and $g$ are Carathéodory functions. We obtain the following system of ordinary differential equations

$$
\left\{\begin{array}{r}
d^{\prime}+y_{n}(t, d)=F_{n}, \\
d(0)=v_{n},
\end{array}\right.
$$

where $\left(F_{n}(t)\right)_{i}=\int_{\Omega} f_{n}(t) \omega_{i} d x$ and $\left(v_{n}\right)_{i}=\int_{\Omega} u_{0_{n}} \omega_{i} d x, i=1, \ldots, n$. Multiplying the first equation of (5.2) by $d(t)$ and using (4.3) and (4.5) one has $F_{n}(t, d) d \geq 0$, we apply the Young inequality to obtain

$$
\frac{1}{2} \frac{\partial}{\partial t}|d(t)|^{2} \leq\left|F_{n}(t)\right||d(t)| \leq \frac{1}{2}\left|F_{n}(t)\right|^{2}+\frac{1}{2}|d(t)|^{2} .
$$

By virtue of Gronwall's lemma one has

$$
|d(t)| \leq C_{n}(T)
$$

Thus, we get $|d(t)-d(0)| \leq 2 C_{n}(T)$. Let $M_{n}=\max _{t \in[0, T]}\left|F_{n}-y_{n}(t, d(t))\right|$ and $q=\min \left\{T, \frac{2 C_{n}(T)}{M_{n}}\right\}$. By the Cauchy-Peano theorem (see for instance [1]) we obtain a local solution in $[0, q]$. Starting with the initial value $q$, we obtain a local solution in $[q, 2 q]$ and so on we get a local solution $d_{n}$ in $\mathcal{C}^{1}([0, T])$. By construction, we know that the function $u_{n}(x, t)=$ $\sum_{i=1}^{n} d_{n, i}(t) \omega_{i}(x)$ which belongs to $X_{n}$ is a Galerkin solution for (1.1) which satisfies

$$
\begin{gathered}
\int_{0}^{\tau} \int_{\Omega} \frac{\partial u_{n}}{\partial t} v d x+\int_{Q_{\tau}} a(x, t, \\
\left.5.3 u_{n}\right) \cdot \nabla v d x d t+\int_{Q_{\tau}} g\left(x, t, u, \nabla u_{n}\right) v d x d t \\
=\int_{Q_{\tau}} f_{n} v d x d t
\end{gathered}
$$


for all $v \in X_{n}$ and all $\tau \in[0, T]$ with $u_{n}(x, 0)=u_{0_{n}}(x)$.

We multiply the equation (5.1) by the coefficients $d_{n, i}(t), i=1,2, \cdots, n$ and we integrate the equation over $[0, \tau]$ for an arbitrarily $\tau \in[0, T]$

$$
\begin{gathered}
\frac{1}{2} \int_{\Omega}\left[\left(u_{n}(t)\right)^{2}\right]_{0}^{T} d x+\int_{Q_{\tau}} a\left(x, t, \nabla u_{n}\right) \cdot \nabla u_{n} d x d t+\int_{Q_{\tau}} g\left(x, t, u_{n}, \nabla u_{n}\right) u_{n} d x d t \\
=\int_{Q_{\tau}} f u_{n} d x d t
\end{gathered}
$$

By (4.3) and (4.5) we can write

$(5.5) \frac{1}{2}\left\|u_{n}(\tau)\right\|_{L^{2}(\Omega)}^{2}+\int_{Q_{\tau}}\left|\nabla u_{n}\right|^{p(x)} d x d t \leq \int_{Q_{\tau}} f u_{n} d x d t+\frac{1}{2}\left\|u_{0}\right\|_{L^{2}(\Omega)}^{2}$.

Then we get

$$
\int_{Q_{\tau}}\left|\nabla u_{n}\right|^{p(x)} d x d t \leq\|f\|_{X_{\tau}^{\prime}}\left|u_{n}\right|_{X_{\tau}}+\frac{1}{2}\left\|u_{0}\right\|_{L^{2}(\Omega)}^{2} .
$$

We distinguish two cases. If $\left\|\nabla u_{n}\right\|_{L^{p(\cdot)}(\Omega)}>1$, we get

$$
\left\|\nabla u_{n}\right\|_{L^{p(\cdot)}(\Omega)}^{p^{-}} \leq \int_{\Omega}\left|\nabla u_{n}\right|^{p(x)} d x .
$$

Thus, we obtain

$$
\left\|u_{n}\right\|_{L^{p^{-}}\left(0, T ; W_{0}^{1, p(\cdot)}(\Omega)\right)} \leq\left(\int_{Q_{\tau}}\left|\nabla u_{n}\right|^{p(x)} d x d t\right)^{\frac{1}{p^{-}}}
$$

which together with (5.6) imply

$$
\begin{aligned}
& \int_{Q_{\tau}}\left|\nabla u_{n}\right|^{p(x)} d x d t \\
& \leq\left\|f_{n}\right\|_{X_{\tau}^{\prime}}\left(\int_{Q_{\tau}}\left|\nabla u_{n}\right|^{p(x)} d x d t\right)^{\frac{1}{p^{-}}}+\left\|f_{n}\right\|_{X_{\tau}^{\prime}}\left\|\nabla u_{n}\right\|_{L^{p(\cdot)}\left(Q_{\tau}\right)}+\frac{1}{2}\left\|u_{0}\right\|_{L^{2}(\Omega)}^{2}
\end{aligned}
$$

By the Young inequality we arrive at

$$
\begin{aligned}
& \int_{Q_{\tau}}\left|\nabla u_{n}\right|^{p(x)} d x d t \\
& \leq 2 \frac{p^{-}-1}{p^{-}}\left(\frac{p^{-}}{2}\right)^{-\frac{1}{p^{-}-1}}\left\|f_{n}\right\|_{X_{\tau}^{\prime}}^{\frac{p^{-}}{p^{-}}}+2\left\|f_{n}\right\|_{X_{\tau}^{\prime}}\left\|\nabla u_{n}\right\|_{L^{p(\cdot)}\left(Q_{\tau}\right)}+\left\|u_{0}\right\|_{L^{2}(\Omega)}^{2}
\end{aligned}
$$


Since $\int_{Q_{\tau}}\left|\nabla u_{n}\right|^{p(x)} d x d t$ is greater than either $\left\|\nabla u_{n}\right\|_{L^{p(\cdot)}\left(Q_{\tau}\right)}^{p^{+}}$or $\left\|\nabla u_{n}\right\|_{L^{p(\cdot)}\left(Q_{\tau}\right)}^{p^{-}}$ according to whether the norm $\left\|\nabla u_{n}\right\|_{L^{p(\cdot)}\left(Q_{\tau}\right)}$ is greater or less than the unity, one can use again the Young inequality in the right-hand side of the above inequality with either the exponent $p^{+}$or $p^{-}$to see that $\left\|\nabla u_{n}\right\|_{L^{p(\cdot)}\left(Q_{\tau}\right)}$ is bounded uniformly in $n$.

While if $\left\|\nabla u_{n}\right\|_{L^{p(\cdot)}(\Omega)} \leq 1$, then

$$
\int_{\Omega}\left|\nabla u_{n}\right|^{p(x)} d x \leq 1
$$

Thus, we get

$$
\left\|\nabla u_{n}\right\|_{L^{p(\cdot)}\left(Q_{\tau}\right)} \leq 1+T
$$

Therefore, in both cases having in mind that $\left\|f_{n}\right\|_{X_{\tau}^{\prime}}$ is uniformly bounded in $n$, we conclude that there is a constant $c>0$, not depending on $n$, such that

$$
\left|u_{n}\right|_{X} \leq c .
$$

From now on, we denote by $c$ various positive real numbers, not depending on $n$, which may vary from line to line. Thanks to (5.5), we get

$$
\left\|u_{n}\right\|_{L^{\infty}\left(0, T ; L^{2}(\Omega)\right)} \leq c .
$$

Going back to (5.4), one has

$$
\int_{Q_{\tau}} a\left(x, t, \nabla u_{n}\right) \cdot \nabla u_{n} d x d t \leq c
$$

and

$$
0 \leq \int_{Q_{\tau}} g\left(x, t, u_{n}, \nabla u_{n}\right) u_{n} d x d t \leq c .
$$

Using (4.4) and (4.5) we can write

$$
\begin{aligned}
& \int_{Q_{\tau}}\left|g\left(x, t, u_{n}, \nabla u_{n}\right)\right| d x d t \\
& \leq \int_{Q_{\tau} \cap\left\{\left|u_{n}\right| \leq 1\right\}}\left|g\left(x, t, u_{n}, \nabla u_{n}\right)\right| d x d t+\int_{Q_{\tau}} g\left(x, t, u_{n}, \nabla u_{n}\right) u_{n} d x d t \\
& \leq b(1)\left(\|\theta\|_{L^{1}\left(Q_{\tau}\right)}+\int_{Q_{\tau}}\left|\nabla u_{n}\right|^{p(x)} d x d t\right)+c \leq c .
\end{aligned}
$$


Hence, the sequence $\left\{g\left(\cdot, \cdot, u_{n}, \nabla u_{n}\right)\right\}_{n}$ remains bounded in $L^{1}(Q)$.

Let us define the operator $A: X \rightarrow X^{\prime}$ by

$$
A u=-\operatorname{diva}(x, t, \nabla u)
$$

then,

$$
\langle A u, \psi\rangle=\int_{Q} a(x, t, \nabla u) \nabla \psi d x d t
$$

for all $u, \psi$ in $X$.

By (4.1) and (5.7) we have

$$
\begin{aligned}
& \int_{Q_{\tau}}\left|a\left(x, t, \nabla u_{n}\right)\right|^{p^{\prime}(x)} d x d t \\
& \leq 2^{\left(p^{\prime}\right)^{+}-1} \int_{Q}\left(C(x, t)^{p^{\prime}(x)}+\left|\nabla u_{n}\right|^{p(x)}\right) d x d t,
\end{aligned}
$$

thus, it follows that

$$
\left\|a\left(x, t, \nabla u_{n}\right)\right\|_{\left(L^{p^{\prime}(\cdot)}(Q)\right)^{N}} \leq c,
$$

which allows us to assert that $\left\{A u_{n}\right\}$ is bounded in $X^{\prime}$ since for all $\psi \in X$

$$
-\left\langle A u_{n}, \psi\right\rangle\left|\leq \int_{Q}\right| a\left(x, t, \nabla u_{n}\right) \cdot \nabla \psi \mid
$$

$\leq\left\|a\left(x, t, \nabla u_{n}\right)\right\|_{\left(L^{\left.p^{(\cdot)}(Q)\right)^{N}}\right.}\|\nabla \psi\|_{\left(L^{p(\cdot)}(Q)\right)^{N}}$

$\leq c|\psi|_{X}$.

Therefore,

$$
\frac{\partial u_{n}}{\partial t}=f-A u_{n}-g\left(x, t, u_{n}, \nabla u_{n}\right) \text { is bounded in } X^{\prime}+L^{1}(Q) .
$$

By virtue of Lemma 3.4, we conclude that there exists a subsequence of $\left(u_{n}\right)$, still indexed by $n$, a function $u \in X \cap \mathcal{C}\left(0, T ; W^{-1,1}(\Omega)\right)$ and a function $\bar{a} \in\left(L^{p^{\prime}(\cdot)}(Q)\right)^{N}$ such that

$$
\begin{array}{rl}
\nabla u_{n} & \rightarrow \nabla u \text { weakly in }\left(L^{p(\cdot)}(Q)\right)^{N}, \\
u_{n} & \rightarrow u \text { strongly in } L^{1}(Q) \text { and a.e. in } Q, \\
u_{n} & *-u \text { weakly }-* \text { in } L^{\infty}\left(0, T ; L^{2}(\Omega)\right), \\
a\left(x, t, \nabla u_{n}\right) & \rightarrow \bar{a} \text { weakly in }\left(L^{p^{\prime}(x)}(Q)\right)^{N} .
\end{array}
$$

STEP II. Almost everywhere convergence of $\nabla u_{n}$

Our aim is to prove that

$$
\nabla u_{n} \longrightarrow \nabla u \quad \text { a.e. in } Q \text {. }
$$

For that, we need apply the following lemma ( see [4] for a similar result): 
Lemma 5.2. Assume that (4.1),(4.2) and (4.3) are satisfied and let $\left(u_{n}\right)$ be a sequence in $X$ such that $u_{n} \longrightarrow u$ weakly in $X$ and

$$
n \longrightarrow \infty \lim \int_{Q}\left[a\left(x, t, \nabla u_{n}\right)-a(x, t, \nabla u)\right] \cdot \nabla\left(u_{n}-u\right) d x d t=0 .
$$

Then $u_{n} \longrightarrow u$ strongly in $X$.

We shall prove that for all $k>0$,

$$
\nabla T_{k}\left(u_{n}\right) \rightarrow \nabla T_{k}(u) \text { strongly in }\left(L^{p(\cdot)}(Q)\right)^{N} .
$$

For $k>0$, we define $S_{k}(t)=\int_{0}^{t} T_{k}(s) d s$, for every $s \in \mathbf{R}$. It's easy to see that $0 \leq S_{k}(r) \leq k|r|$. Note that $T_{k}\left(u_{n}\right) \in X \hookrightarrow L^{1}\left(0, T ; W_{0}^{1,1}(\Omega)\right)$ and hence $\nabla T_{k}\left(u_{n}\right)=\nabla u_{n} \chi_{\left\{\left|u_{n}\right|<k\right\}}$, a.e. in $Q$. Choosing $T_{k}\left(u_{n}\right)$ as test function in the equation (5.3) and then using (4.5), we obtain

$$
\int_{\Omega} S_{k}\left(u_{n}(T)\right)-S_{k}\left(u_{n}(0)\right) d x+\int_{Q} a\left(x, t, \nabla u_{n}\right) \nabla T_{k}\left(u_{n}\right) d x d t \leq\left\langle f, T_{k}\left(u_{n}\right)\right\rangle,
$$

Using (4.3) and (5.8) we get

$$
\begin{aligned}
\int_{Q}\left|\nabla T_{k}\left(u_{n}\right)\right|^{p(x)} & \leq \int_{Q} a\left(x, t, \nabla u_{n}\right) \cdot \nabla T_{k}\left(u_{n}\right) d x d t \\
& =\int_{\left\{\left|u_{n}\right| \leq k\right\}} a\left(x, t, \nabla u_{n}\right) \cdot \nabla u_{n} d x d t \\
& \leq c,
\end{aligned}
$$

the sequence $\left\{\nabla T_{k}\left(u_{n}\right)\right\}_{n}$ is uniformly bounded in $\left(L^{p(\cdot)}(Q)\right)^{N}$ so that $\nabla T_{k}\left(u_{n}\right) \rightarrow v_{k}$ weakly in $\left(L^{p(\cdot)}(Q)\right)^{N}$. Moreover, an application of Lebesgue's dominated convergence theorem gives $T_{k}\left(u_{n}\right) \rightarrow T_{k}(u)$ strongly in $L^{p(\cdot)}(Q)$.

Let $\Phi=\left(\phi_{1}, \phi_{2}, \ldots, \phi_{N}\right)$ with $\phi_{i} \in \mathcal{C}_{0}^{\infty}(Q)$ for every $i=1,2, \ldots, N$.

Setting $\phi=-\operatorname{div} \Phi$ one has $\Phi \in X^{\prime}$. On one hand

$$
\left\langle\phi, T_{k}\left(u_{n}\right)\right\rangle_{X^{\prime}, X}=\int_{Q} \Phi \cdot \nabla T_{k}\left(u_{n}\right) d x d t \rightarrow \int_{Q} \Phi \cdot v_{k} d x d t .
$$

On the other hand

$$
\begin{aligned}
& \left\langle\phi, T_{k}\left(u_{n}\right)\right\rangle_{X^{\prime}, X}=-\sum_{i=1}^{N} \int_{Q} \frac{\partial \phi}{\partial x_{i}} T_{k}\left(u_{n}\right) d x d t \\
& \rightarrow-\sum_{i=1}^{N} \int_{Q} \frac{\partial \phi}{\partial x_{i}} T_{k}(u) d x d t=\int_{Q} \Phi \cdot \nabla T_{k}(u) d x d t=\left\langle\phi, T_{k}(u)\right\rangle_{X^{\prime}, X}
\end{aligned}
$$


Therefore, we get $v_{k}=\nabla T_{k}(u)$ a.e. in $Q$ and for all $k>0$

$$
\begin{aligned}
\nabla T_{k}\left(u_{n}\right) & \rightarrow \nabla T_{k}(u) \text { weakly in }\left(L^{p(\cdot)}(Q)\right)^{N}, \\
T_{k}\left(u_{n}\right) & \rightarrow T_{k}(u) \text { weakly in } X .
\end{aligned}
$$

By virtue of (5.10) and Lebesgue's dominated convergence theorem we have

$$
T_{k}\left(u_{n}\right) \rightarrow T_{k}(u) \text { strongly in } L^{p(\cdot)}(Q) \text { a.e. in } Q, \forall k>0 \text {. }
$$

Fix $k>0$ and let $\varphi(s)=s e^{\delta s^{2}},(\delta>0)$. It's easy to check that if $\delta \geq\left(\frac{b(k)}{2}\right)^{2}$, one has

$$
\varphi^{\prime}(s)-b(k)|\varphi(s)| \geq \frac{1}{2}, \quad \forall s \in \mathbf{R} .
$$

We define the mollification with respect to time of $T_{k}(u)$ given by

$$
T_{k}(u)_{\mu}(x, t)=\mu \int_{-\infty}^{t} T_{k}(u)(x, s) e^{\mu(s-t)} d s,
$$

extending $T_{k}(u)$ by zero for $s<0$. Observe that $T_{k}(u)_{\mu} \in X \cap L^{\infty}(Q)$ verifying

$\left|T_{k}(u)_{\mu}(x, t)\right| \leq k\left(1-e^{-\mu t}\right)$ and $\frac{\partial T_{k}(u)_{\mu}}{\partial t}=\mu\left(T_{k}(u)-T_{k}(u)_{\mu}(x, t)\right)$ a.e. in $Q$.

Let $\left(\psi_{i}\right) \subset C_{0}^{\infty}(\Omega)$ such that $\psi_{i} \rightarrow u_{0}$ in $L^{2}(\Omega)$. Set $\omega_{\mu}^{i}=T_{k}(u)_{\mu}+$ $e^{-\mu t} T_{k}\left(\psi_{i}\right)$. Note that $\omega_{\mu}^{i}$ is a smooth function having the following properties (see [12])

$$
\frac{\partial}{\partial t}\left(\omega_{\mu}^{i}\right)=\mu\left(T_{k}(u)-\omega_{\mu}^{i}\right), \quad \omega_{\mu}^{i}(0)=T_{k}\left(\psi_{i}\right), \quad\left|\omega_{\mu}^{i}\right| \leq k .
$$

Moreover, we can easily check that

$$
\omega_{\mu}^{i} \rightarrow T_{k}(u) \text { a.e. in } Q \text {, weak-* in } L^{\infty}(Q) \text { and strongly in } X \text {, as } \mu \rightarrow \infty \text {. }
$$

Using $z_{n}^{\mu, i}=\varphi\left(T_{k}\left(u_{n}\right)-\omega_{\mu}^{i}\right)$ which belong to $X \cap L^{\infty}(Q)$ as test function in (5.3) we get

$$
\begin{aligned}
& \left\langle u_{n}^{\prime}, z_{n}^{\mu, i}\right\rangle+\int_{Q} a\left(x, t, \nabla u_{n}\right)\left(\nabla T_{k}\left(u_{n}\right)-\nabla \omega_{\mu}^{i}\right) \varphi^{\prime}\left(T_{k}\left(u_{n}\right)-\omega_{\mu}^{i}\right) d x d t \\
& +\int_{Q} g\left(x, t, u_{n}, \nabla u_{n}\right) \varphi\left(T_{k}\left(u_{n}\right)-\omega_{\mu}^{i}\right) d x d t=\left\langle f, z_{n}^{\mu, i}\right\rangle
\end{aligned}
$$


which implies by the fact $g\left(x, t, u_{n}, \nabla u_{n}\right) \varphi\left(T_{k}\left(u_{n}\right)-\omega_{\mu}^{i}\right) \geq 0$ on $\left\{(x, t) \in Q:\left|u_{n}(x, t)\right|>k\right\}$

$$
\begin{aligned}
\left\langle u_{n}^{\prime}, z_{n}^{\mu, i}\right\rangle & +\int_{Q} a\left(x, t, \nabla u_{n}\right)\left(\nabla T_{k}\left(u_{n}\right)-\nabla \omega_{\mu}^{i}\right) \varphi^{\prime}\left(T_{k}\left(u_{n}\right)-\omega_{\mu}^{i}\right) d x d t \\
& +\int_{\left\{\left|u_{n}\right|>k\right\}} g\left(x, t, u_{n}, \nabla u_{n}\right) \varphi\left(T_{k}\left(u_{n}\right)-\omega_{\mu}^{i}\right) d x d t \leq\left\langle f, z_{n}^{\mu, i}\right\rangle .
\end{aligned}
$$

Since $f \in X^{\prime}, T_{k}\left(u_{n}\right)-\omega_{\mu}^{i} \rightarrow T_{k}(u)-\omega_{\mu}^{i}$ weakly in $X$ as $n \rightarrow \infty$ and $T_{k}(u)_{\mu}+e^{-\mu t} T_{k}\left(\psi_{i}\right) \longrightarrow T_{k}(u)$ in $X$ as $\mu \longrightarrow \infty$, we have

$$
\left\langle f, z_{n}^{\mu, i}\right\rangle=\varepsilon(n, \mu)
$$

By setting $G_{k}(s)=s-T_{k}(s)$, we have:

$$
\begin{aligned}
\left\langle u_{n}^{\prime}, z_{n}^{\mu, i}\right\rangle & =\int_{Q} u_{n}^{\prime} \varphi\left(T_{k}\left(u_{n}\right)-\omega_{\mu}^{i}\right) d x d t \\
& =\int_{Q}\left(\left(T_{k}\left(u_{n}\right)\right)^{\prime}+\left(G_{k}\left(u_{n}\right)\right)^{\prime}\right) \varphi\left(T_{k}\left(u_{n}\right)-\omega_{\mu}^{i}\right) d x d t \\
& =\int_{Q}\left(T_{k}\left(u_{n}\right)-\omega_{\mu}^{i}\right)^{\prime} \varphi\left(T_{k}\left(u_{n}\right)-\omega_{\mu}^{i}\right) d x d t \\
& +\int_{Q}\left(\omega_{\mu}^{i}\right)^{\prime} \varphi\left(T_{k}\left(u_{n}\right)-\omega_{\mu}^{i}\right) d x d t \\
& +\int_{Q}\left(G_{k}\left(u_{n}\right)^{\prime} \varphi\left(T_{k}\left(u_{n}\right)-\omega_{\mu}^{i}\right) d x d t\right. \\
& =J_{1}+J_{2}+J_{3} .
\end{aligned}
$$

Let $\Phi(s)=\int_{0}^{s} \varphi(r) d r$, remarking that $\Phi(s) \geq 0$, one has

$$
J_{1}=\left[\int_{\Omega} \Phi\left(T_{k}\left(u_{n}\right)-\omega_{\mu}^{i}\right)(t) d x\right]_{0}^{T} \geq-\int_{\Omega} \Phi\left(T_{k}\left(u_{n}\right)(0)-T_{k}\left(\psi_{i}\right)\right) d x i \rightarrow \infty \longrightarrow 0,
$$

then $J_{1} \geq \varepsilon(i)$. On other hand, since $\left(\omega_{\mu}^{i}\right)^{\prime}=\mu\left(T_{k}\left(u_{n}\right)-\omega_{\mu}^{i}\right)$ and $\varphi(s) s \geq 0$, we have

$$
J_{2} \geq \mu \int_{Q}\left(T_{k}(u)-T_{k}\left(u_{n}\right) \varphi\left(T_{k}\left(u_{n}\right)-\omega_{\mu}^{i}\right) d x d t n \rightarrow \infty \longrightarrow 0,\right.
$$

hence $J_{2} \geq \varepsilon(n)$. For what concerns $J_{3}$, one has by integrating by parts

$$
\begin{aligned}
J_{3} & =-\int_{Q} G_{k}\left(u_{n}\right) \varphi^{\prime}\left(T_{k}\left(u_{n}\right)-\omega_{\mu}^{i}\right)\left(T_{k}\left(u_{n}\right)-\omega_{\mu}^{i}\right)^{\prime} d x d t \\
& +\left[\int_{\Omega} G_{k}\left(u_{n}\right) \varphi\left(T_{k}\left(u_{n}\right)-\omega_{\mu}^{i}\right)\right]_{0}^{T},
\end{aligned}
$$


if we take in consideration that $\left(T_{k}\left(u_{n}\right)\right)^{\prime}=0$ on $\left\{\left|u_{n}\right|>k\right\}$ and $G_{k}\left(u_{n}\right)=0$ on $\left\{\left|u_{n}\right| \leq k\right\}$, we have

$$
\left[\int_{\Omega} G_{k}\left(u_{n}\right) \varphi\left(T_{k}\left(u_{n}\right)-T_{k}\left(u_{n}\right)\right)\right]_{0}^{T} \geq-\int_{\Omega} G_{k}\left(u_{0}\right) \varphi\left(T_{k}\left(u_{0}\right)-T_{k}\left(\psi_{i}\right)\right) d x
$$

thus

$$
\begin{aligned}
J_{3} \geq & -\int_{Q} G_{k}\left(u_{n}\right) \varphi^{\prime}\left(T_{k}\left(u_{n}\right)-\omega_{\mu}^{i}\right)\left(T_{k}\left(u_{n}\right)-\omega_{\mu}^{i}\right)^{\prime} d x d t \\
& +\int_{\Omega} G_{k}\left(u_{0}\right) \varphi\left(T_{k}\left(u_{0}\right)-T_{k}\left(\psi_{i}\right)\right) d x \\
= & \mu-\int_{Q} G_{k}\left(u_{n}\right) \varphi^{\prime}\left(T_{k}\left(u_{n}\right)-\omega_{\mu}^{i}\right)\left(\omega_{\mu}^{i}\right)^{\prime} d x d t \\
& +\int_{\Omega} G_{k}\left(u_{0}\right) \varphi\left(T_{k}\left(u_{0}\right)-T_{k}\left(\psi_{i}\right)\right) d x \\
& n \rightarrow \infty \longrightarrow \mu-\int_{Q} G_{k}\left(u_{n}\right) \varphi^{\prime}\left(T_{k}(u)-\omega_{\mu}^{i}\right)\left(\omega_{\mu}^{i}\right)^{\prime} d x d t \\
& +\int_{\Omega} G_{k}\left(u_{0}\right) \varphi\left(T_{k}\left(u_{0}\right)-T_{k}\left(\psi_{i}\right)\right) d x \\
\geq & -\int_{\Omega} G_{k}\left(u_{0}\right) \varphi\left(T_{k}\left(u_{0}\right)-T_{k}\left(\psi_{i}\right)\right) d x i \rightarrow \infty \longrightarrow 0 .
\end{aligned}
$$

by consequent $J_{3} \geq \varepsilon(n, i)$. Combining all these estimates, we get

$$
\left\langle\frac{\partial u_{n}}{\partial t}, \varphi\left(T_{k}\left(u_{n}\right)-\omega_{\mu}^{i}\right)\right\rangle \geq \varepsilon(n, i) .
$$

Let $s>0$ and set $Q^{s}:=\left\{(x, t) \in Q ;\left|\nabla T_{k}(u(x, t))\right| \leq s\right\}$. Denoting by $\chi_{s}$ the characteristic function of $Q^{s}$, the second term of the left-hand side of (5.12) reads as

$$
\begin{aligned}
& \int_{Q}\left[a\left(x, t, \nabla T_{k}\left(u_{n}\right)\right)-a\left(x, t, \nabla T_{k}(u) \chi_{s}\right)\right]\left[\nabla T_{k}\left(u_{n}\right)-\nabla T_{k}(u) \chi_{s}\right] \\
& \varphi^{\prime}\left(T_{k}\left(u_{n}\right)-\omega_{\mu}^{i}\right) d x d t+\int_{Q} a\left(x, t, \nabla T_{k}(u)\right)\left(\nabla T_{k}\left(u_{n}\right)-\nabla T_{k}(u) \chi_{s}\right) \\
& \varphi^{\prime}\left(T_{k}\left(u_{n}\right)-\omega_{\mu}^{i}\right) d x d t+\int_{Q} a\left(x, t, \nabla T_{k}\left(u_{n}\right)\right) \nabla T_{k}(u) \chi_{s} \\
& \varphi^{\prime}\left(T_{k}\left(u_{n}\right)-\omega_{\mu}^{i}\right) d x d t-\int_{Q} a\left(x, t, \nabla u_{n}\right) \nabla \omega_{\mu}^{i} \chi_{s} \varphi^{\prime}\left(T_{k}\left(u_{n}\right)-\omega_{\mu}^{i}\right) d x d t \\
& =I_{1}+I_{2}+I_{3}+I_{4} .
\end{aligned}
$$

We have

$$
\begin{gathered}
a\left(x, t, T_{k}\left(u_{n}\right), \nabla T_{k}(u)\right) \varphi^{\prime}\left(T_{k}\left(u_{n}\right)-\omega_{\mu}^{i}\right) n \rightarrow \infty \rightarrow a\left(x, t, T_{k}(u), \nabla T_{k}(u)\right) \\
\varphi^{\prime}\left(T_{k}(u)-\omega_{\mu}^{i}\right)
\end{gathered}
$$

strongly in $L^{p^{\prime}(\cdot)}(Q)$.

By the fact that $\frac{\partial T_{k}\left(u_{n}\right)}{\partial x_{i}} n \rightarrow \infty \longrightarrow \frac{\partial T_{k}(u)}{\partial x_{i}}$ weakly in $L^{p(\cdot)}(Q)$ and that $\varphi^{\prime}\left(T_{k}(u)-T_{k}(u)_{\mu}-e^{-\mu t} T_{k}\left(\psi_{i}\right)\right) \rightarrow 1$ a.e. in $Q$ and is uniformly bounded by $\varphi^{\prime}(2 k)$ and by using Lebesgue's theorem, we can write 


$$
\begin{aligned}
J_{2}= & \int_{Q} a\left(x, t, \nabla T_{k}(u)\right)\left(\nabla T_{k}(u)-\nabla T_{k}(u) \chi_{s}\right) \varphi^{\prime}\left(T_{k}(u)-\omega_{\mu}^{i}\right) d x d t+\varepsilon(n) \\
& =\int_{Q \backslash Q^{s}} a(x, t, 0) \nabla T_{k}(u) d x d t+\varepsilon(n, \mu),
\end{aligned}
$$

by letting $s \rightarrow \infty$, we conclude that $J_{2}=\varepsilon(n, \mu, s)$. About $j_{3}$, we have

$$
\begin{aligned}
J_{3}= & \int_{\left\{\left|u_{n}\right| \leq k\right\}} a\left(x, t, \nabla u_{n}\right) \nabla T_{k}(u) \chi_{s} \varphi^{\prime}\left(T_{k}\left(u_{n}\right)-\omega_{\mu}^{i}\right) d x d t \\
& +\int_{\left\{\left|u_{n}\right|>k\right\}} a(x, t, 0) \nabla T_{k}(u) \chi_{s} \varphi^{\prime}\left(T_{k}\left(u_{n}\right)-\omega_{\mu}^{i}\right) d x d t
\end{aligned}
$$

by letting $n \rightarrow \infty$ and due to the weak convergence of $a\left(x, t, \nabla u_{n}\right)$ to $\bar{a}$ in $\left(L^{p^{\prime}(\cdot)}(Q)\right)^{N}$, we have

$$
\begin{aligned}
J_{3}= & \int_{\{|u| \leq k\}} \bar{a} \nabla T_{k}(u) \chi_{s} \varphi^{\prime}\left(T_{k}(u)-\omega_{\mu}^{i}\right) d x d t \\
& +\int_{\{|u|>k\}} a(x, t, 0) \nabla T_{k}(u) \cdot \chi_{s} \varphi^{\prime}\left(T_{k}(u)-\omega_{\mu}^{i}\right) d x d t+\varepsilon(n),
\end{aligned}
$$

in which we can let $\mu \rightarrow \infty$ to obtain $J_{3}=\int_{Q} \bar{a} \nabla T_{k}(u) \xi_{s} d x d t+\varepsilon(n, \mu)$, consequently, by letting $s \rightarrow \infty$,

$$
J_{3}=\int_{Q} \bar{a} \nabla T_{k}(u) \xi_{s} d x d t+\varepsilon(n, \mu, s) .
$$

For $j_{4}$, we have as above, by letting first $n$ then $\mu$ go to infinity

$$
\begin{aligned}
J_{4} & =\int_{Q} \bar{a} \nabla \omega_{\mu}^{i} \varphi^{\prime}\left(T_{k}(u)-\omega_{\mu}^{i}\right) d x d t+\varepsilon(n) \\
& =-\int_{Q} \bar{a} \nabla T_{k}(u) d x d t+\varepsilon(n, \mu) .
\end{aligned}
$$

Thus

$$
\begin{aligned}
& \int_{Q} a\left(x, t, \nabla u_{n}\right)\left[\nabla T_{k}\left(u_{n}\right)-\nabla \omega_{\mu}^{i}\right] \varphi^{\prime}\left(T_{k}\left(u_{n}\right)-\omega_{\mu}^{i}\right) d x d t \\
& \int_{Q}\left[a\left(x, t, \nabla T_{k}\left(u_{n}\right)\right)-a\left(x, t, \nabla T_{k}(u) \chi_{s}\right)\right]\left[\nabla T_{k}\left(u_{n}\right)-\nabla T_{k}(u) \chi_{s}\right]
\end{aligned}
$$$$
\varphi^{\prime}\left(T_{k}\left(u_{n}\right)-\omega_{\mu}^{i}\right) d x d t+\varepsilon(n, \mu, s) \text {. }
$$

The third term of the left-hand of (5.12) can be estimated as

$$
\begin{aligned}
& \left|\int_{\{|u| \leq k\}} g\left(x, t, u_{n}, \nabla u_{n}\right) \varphi\left(T_{k}\left(u_{n}\right)-\omega_{\mu}^{i}\right) d x d t\right| \\
& \leq b(k) \int_{Q}\left(\theta(x, t)+\left|\nabla u_{n}\right|^{p(x)}\right)\left|\varphi\left(T_{k}\left(u_{n}\right)-\omega_{\mu}^{i}\right)\right| d x d t \\
& +b(k) \int_{Q} a\left(x, t, \nabla T_{k}\left(u_{n}\right)\right) \nabla T_{k}(u)\left|\varphi\left(T_{k}\left(u_{n}\right)-\omega_{\mu}^{i}\right)\right| d x d t
\end{aligned}
$$

since $\theta(x, t) \in L^{1}(Q)$ and by estimation of (5.7), we have

$$
b(k) \int_{Q}\left(\theta(x, t)+\left|\nabla u_{n}\right|^{p(x)}\right)\left|\varphi\left(T_{k}\left(u_{n}\right)-\omega_{\mu}^{i}\right)\right| d x d t=\varepsilon(n, \mu) .
$$


The second term of (5.16) reads as

$$
\begin{aligned}
& b(k) \int_{Q}\left(\theta(x, t)+\left|\nabla u_{n}\right|^{p(x)}\right)\left|\varphi\left(T_{k}\left(u_{n}\right)-\omega_{\mu}^{i}\right)\right| d x d t \\
= & b(k) \int_{Q}\left[a\left(x, t, \nabla T_{k}\left(u_{n}\right)\right)-a\left(x, t, \nabla T_{k}(u) \chi_{s}\right)\right]\left[\nabla T_{k}\left(u_{n}\right)-\nabla T_{k}(u) \cdot \chi_{s}\right] \\
& \left.\left|\varphi\left(T_{k}\left(u_{n}\right)-\omega_{\mu}^{i}\right)\right| d x d t+(k) \int_{Q} a\left(x, t, \nabla T_{k}(u) \chi_{s}\right)\right] \\
& {\left[\nabla T_{k}\left(u_{n}\right)-\nabla T_{k}(u) \chi_{s}\right]\left|\varphi\left(T_{k}\left(u_{n}\right)-\omega_{\mu}^{i}\right)\right| d x d t } \\
& +b(k) \int_{Q} a\left(x, t, \nabla T_{k}\left(u_{n}\right)\right) \nabla T_{k}(u) \chi_{s}\left|\varphi\left(T_{k}\left(u_{n}\right)-\omega_{\mu}^{i}\right)\right| d x d t
\end{aligned}
$$

As above, we can write

$$
\begin{aligned}
& \left|\int_{\{|u| \leq k\}} g\left(x, t, u_{n}, \nabla u_{n}\right) \varphi\left(T_{k}\left(u_{n}\right)-\omega_{\mu}^{i}\right) d x d t\right| \\
& \leq b(k) \int_{Q}\left[a\left(x, t, \nabla T_{k}\left(u_{n}\right)\right)-a\left(x, t, \nabla T_{k}(u) \chi_{s}\right)\right]\left[\nabla T_{k}\left(u_{n}\right)-\nabla T_{k}(u) \chi_{s}\right] \\
& \left|\varphi\left(T_{k}\left(u_{n}\right)-\omega_{\mu}^{i}\right)\right| d x d t+\varepsilon(n, \mu) .
\end{aligned}
$$

Combining (5.12), (5.13), (5.14) and (5.15) we get

$$
\begin{aligned}
& \int_{Q}\left[a\left(x, t, \nabla T_{k}\left(u_{n}\right)\right)-a\left(x, t, \nabla T_{k}(u) \chi_{s}\right)\right]\left[\nabla T_{k}\left(u_{n}\right)-\nabla T_{k}(u) \chi_{s}\right] \\
& {\left[\varphi^{\prime}\left(T_{k}\left(u_{n}\right)-\omega_{\mu}^{i}\right)-b(k)\left|\varphi\left(T_{k}\left(u_{n}\right)-\omega_{\mu}^{i}\right)\right|\right] d x d t \leq \varepsilon(n, \mu, i, s),}
\end{aligned}
$$

by fact that $\varphi^{\prime}(s)-b(k)|\varphi(s)| \geq \frac{1}{2} \quad \forall s \in \mathbf{R}$, we have

$$
\begin{gathered}
\int_{Q}\left[a\left(x, t, \nabla T_{k}\left(u_{n}\right)\right)-a\left(x, t, \nabla T_{k}(u) \chi_{s}\right)\right]\left[\nabla T_{k}\left(u_{n}\right)-\nabla T_{k}(u) \chi_{s}\right] \\
d x d t \leq 2 \varepsilon(n, \mu, i, s) .
\end{gathered}
$$

On other hand, we have with (4.2) for $r \leq s$

$$
\begin{aligned}
0 & \leq \int_{Q^{r}}\left[a\left(x, t, \nabla T_{k}\left(u_{n}\right)\right)-a\left(x, t, \nabla T_{k}(u)\right)\right]\left[\nabla T_{k}\left(u_{n}\right)-\nabla T_{k}(u)\right] d x d t \\
& \leq \int_{Q^{s}}\left[a\left(x, t, \nabla T_{k}\left(u_{n}\right)\right)-a\left(x, t, \nabla T_{k}(u) \chi_{s}\right)\right]\left[\nabla T_{k}\left(u_{n}\right)-\nabla T_{k}(u) \chi_{s}\right] d x d t \\
& \leq \varepsilon(n, \mu, i, s) .
\end{aligned}
$$

which implies by passing to the limit sup over $n$ that

$$
\begin{aligned}
0 & \leq n \rightarrow \infty \lim \sup \int_{Q}\left[a\left(x, t, \nabla T_{k}\left(u_{n}\right)\right)-a\left(x, t, \nabla T_{k}(u) \chi_{s}\right)\right] \\
& {\left[\nabla T_{k}\left(u_{n}\right)-\nabla T_{k}(u) \chi_{s}\right] d x d t } \\
& \leq 2 n \rightarrow \infty \lim \varepsilon(n, \mu,, i, s),
\end{aligned}
$$


in which we let successively $\mu \rightarrow \infty, i \rightarrow \infty$ and $s \rightarrow \infty$ to obtain

$$
\begin{aligned}
& \int_{Q^{r}}\left[a\left(x, t, \nabla T_{k}\left(u_{n}\right)\right)-a\left(x, t, \nabla T_{k}(u)\right)\right]\left[\nabla T_{k}\left(u_{n}\right)-\nabla T_{k}(u)\right], \\
& d x d t \longrightarrow 0, \text { as } n \rightarrow \infty .
\end{aligned}
$$

Hence by lemma 5.2 we have

$$
T_{k}\left(u_{n}\right) \longrightarrow T_{k}(u) \text { strongly in } X^{r} \forall k>0 .
$$

We also deduce that for a subsequence denoted $\left(u_{n}\right)$

$$
T_{k}\left(u_{n}\right) \longrightarrow T_{k}(u) \text { a.e. in } Q^{r} \forall k>0 \text {. }
$$

Since $r$ and $k$ are arbitrary, there exists a diagonal subsequence of $\left(u_{n}\right)$ also denoted $\left(u_{n}\right)$ in $r$ and $k$ such that

$$
\nabla u_{n} \longrightarrow \nabla u \quad \text { a.e. in } Q .
$$

Since $a(x, t,$.$) and g(x, t, .,$.$) are continuous, then$

$$
a\left(x, t, \nabla u_{n}\right) \longrightarrow a(x, t, \nabla u) \text { a.e. in Q. }
$$

If we take in consideration that $a\left(x, t, \nabla u_{n}\right)$ is bounded in $\left(L^{p^{\prime}(\cdot)}(Q)\right)^{N}$, then by lemma 2.2

$$
a\left(x, t, \nabla u_{n}\right) \longrightarrow a(x, t, \nabla u) \quad \text { weakly in }\left(L^{p^{\prime}(\cdot)}(Q)\right)^{N} .
$$

\section{STEP III. Equi-integrability of $g\left(x, t, u_{n}, \nabla u_{n}\right)$ on $Q$}

Let $k>0$ and let $E$ a measurable subset of $Q$ and $\varepsilon>0$ be fixed. Since $g$ verifies the sign condition, then by using (5.9), we have

$$
\begin{aligned}
& \int_{E}\left|g\left(x, t, u_{n}, \nabla u_{n}\right)\right| d x d t \\
& =\int_{E \cap\left\{\left|u_{n}\right| \leq k\right\}} g\left(x, t, u_{n}, \nabla u_{n}\right) d x d t+\int_{E \cap\left\{\left|u_{n}\right|>k\right\}} g\left(x, t, u_{n}, \nabla u_{n}\right) d x d t \\
& \leq \int_{E \cap\left\{\left|u_{n}\right| \leq k\right\}} g\left(x, t, u_{n}, \nabla u_{n}\right) d x d t+\frac{1}{k} \int_{E} g\left(x, t, u_{n}, \nabla u_{n}\right) u_{n} d x d t \\
& \leq \int_{E \cap\left\{\left|u_{n}\right| \leq k\right\}} g\left(x, t, T_{k}\left(u_{n}\right), \nabla T_{k}\left(u_{n}\right)\right) d x d t+\frac{1}{k} c \\
& \leq b(k) \int_{E} \theta(x, t) d x d t+b(k) \int_{E}\left|\nabla T_{k}\left(u_{n}\right)\right|^{p(x)} d x d t+\frac{c}{k} .
\end{aligned}
$$

The strong convergence in (5.11) implies that there exists $\delta>0$ such that meas $(\mathrm{E})<\delta \Longrightarrow \int_{E}\left|\nabla T_{k}\left(u_{n}\right)\right|^{p(x)} d x d t \leq \frac{\varepsilon}{3}$. Since $\theta \in L^{1}(Q)$, then 
$b(k) \int_{E} \theta(x, t) d x d t \leq \frac{\varepsilon}{3}$ and choosing $k$ large nought such that $\frac{c}{k} \leq \frac{\varepsilon}{3}$.

Hence, there exists $\delta>0$ such that meas $(\mathrm{E})<\delta \Longrightarrow \int_{E}\left|g\left(x, t, u_{n}, \nabla u_{n}\right)\right| d x d t \leq \varepsilon$ $\forall n \in \mathbf{N}$. Thus $\left|g\left(x, t, u_{n}, \nabla u_{n}\right)\right|$ is uniformly equi-integrable on $Q$.

Recall that $u_{n} \longrightarrow u$ a.e. in $Q$ and $\nabla u_{n} \longrightarrow \nabla u$ a.e. in $Q$, therefore because $g(x, t, . .$.$) is continuous$

$$
g\left(x, t, u_{n}, \nabla u_{n}\right) \longrightarrow g(x, t, u, \nabla u) \quad \text { a.e. in } Q .
$$

By Vitali's theorem, we obtain

$$
g\left(x, t, u_{n}, \nabla u_{n}\right) \longrightarrow g(x, t, u, \nabla u) \quad \text { strongly in } \quad L^{1}(Q) .
$$

Since $g$ is continuous in the two last arguments, we have

$$
g\left(x, t, u_{n}, \nabla u_{n}\right) u_{n} \rightarrow g(x, t, u, \nabla u) u \quad \text { a.e. in } Q,
$$

Moreover, we have $g\left(x, t, u_{n}, \nabla u_{n}\right) u_{n} \geq 0$ a.e. it follows by (5.9) and Fatou's lemma that

$$
g(x, t, u, \nabla u) u \in L^{1}(Q) .
$$

\section{STEP IV. Passage to the limit}

Recall that $u \in X \cap C\left(0, T ; W^{-1,1}(\Omega)\right)$ and in particular $u \in X \cap L^{2}(Q) \cap C\left([0, T], L^{2}(\Omega)\right)$. In addition $\frac{\partial u}{\partial t} \in X^{\prime}+L^{1}(Q)$. Let $\tau \in$ $(0, T]$. For all $\varphi \in C^{1}\left([0, \tau] ; \mathcal{C}_{0}^{\infty}(\Omega)\right)$ with $\varphi(\cdot, t)=0$ in a neighborhood of $T$, we can write

$$
\int_{Q_{\tau}} \frac{\partial u_{n}}{\partial t} \varphi d x=\int_{\Omega}\left(u_{n}(x, \tau) \varphi(x, \tau)-u_{n}(x, 0) \varphi(x, 0)\right) d x-\int_{Q_{\tau}} u_{n} \frac{\partial \varphi}{\partial t} d x .
$$

Since $u_{n} \rightarrow u$ in $L^{2}(\Omega)$ and $u_{n} \rightarrow u$ in $L^{2}(Q)$, we obtain

$$
\lim _{n \rightarrow+\infty} \int_{Q_{\tau}} \frac{\partial u_{n}}{\partial t} \varphi d x=\left[\int_{\Omega} u \varphi d x\right]_{0}^{\tau}-\int_{Q_{\tau}} u \frac{\partial \varphi}{\partial t} d x
$$

Therefore, passing to the limit in (5.3) we get

$$
\begin{gathered}
-\int_{Q_{\tau}} u \frac{\partial \varphi}{\partial t} d x+\left[\int_{\Omega} u \varphi d x\right]_{0}^{\tau} \int_{Q_{\tau}} a(x, t, \nabla u) \cdot \nabla \varphi d x d t \\
+\int_{Q_{\tau}} g(x, t, u, \nabla u) \varphi d x d t=\langle f, \varphi\rangle_{X^{\prime}, X} .
\end{gathered}
$$


Let now $v \in X \cap L^{2}(Q)$ with $\frac{\partial v}{\partial t} \in X^{\prime}$. By Lemma 3.5, there exists a sequence $\left\{v_{\epsilon}\right\}$ in $C_{0}^{\infty}\left([0, T], C_{0}^{\infty}(\Omega)\right)$ such that

$$
\begin{aligned}
v_{\epsilon} & \rightarrow v \text { strongly in } X \cap L^{2}(Q) \text { and } \\
\frac{\partial v_{\epsilon}}{\partial t} & \rightarrow \frac{\partial v}{\partial t} \text { in } X^{\prime}+L^{1}(Q) .
\end{aligned}
$$

Let $\tau \in(0, T]$. Inserting $\phi=v_{\epsilon} \chi_{(0, \tau)} \in C^{1}\left([0, T] ; \mathcal{C}_{0}^{\infty}(\Omega)\right)$ as test function in (5.17) we get

$$
\begin{gathered}
-\int_{Q_{\tau}} u \frac{\partial v_{\epsilon}}{\partial t} d x+\left[\int_{\Omega} u v_{\epsilon} d x\right]_{0}^{\tau}+\int_{Q_{\tau}} a(x, t, \nabla u) \cdot \nabla v_{\epsilon} d x d t \\
+\int_{Q_{\tau}} g(x, t, u, \nabla u) v_{\epsilon} d x d t=\left\langle f, v_{\epsilon}\right\rangle_{X^{\prime}, X}
\end{gathered}
$$

Letting $\epsilon \rightarrow 0$, we obtain

$$
\begin{gathered}
-\left\langle\frac{\partial v}{\partial t}, u\right\rangle_{X^{\prime}, X}+\left[\int_{\Omega} u v d x\right]_{0}^{\tau}+\int_{Q_{\tau}} a(x, t, \nabla u) \cdot \nabla v d x d t \\
+\int_{Q_{\tau}} g(x, t, u, \nabla u) v d x d t=\langle f, v\rangle_{X^{\prime}, X} .
\end{gathered}
$$

The proof of Theorem 4.1 is completed.

\section{References}

[1] H. Amann, Ordinary differential equations: an introduction to nonlinear analysis. Berlin: De Gruyter, 1990.

[2] S. Antontsev and S. Shmarev, "Anisotropic parabolic equations with variable nonlinearity", Publicacions matemàtiques, vol. 53, pp. 355-399, 2009.doi: 10.5565/publmat_53209_04

[3] M. Bendahmane, P. Wittbold, and A. Zimmermann, "Renormalized solutions for a nonlinear parabolic equation with variable exponents and $\mathrm{L}^{1}$-data", Journal of differential equations, vol. 249, no. 6, pp. 1483-1515, 2010. doi: 10.1016/j.jde.2010.05.011

[4] L. Boccardo, F. Murat, and J. P. Puel, "Existence of bounded solutions for non linear elliptic unilateral problems", Annali di matematica pura ed applicata, vol. 152, no. 1, pp. 183-196, 1988. doi: 10.1007/ bf01766148 
[5] Y. Chen, S. Levine, and M. Rao, "Variable exponent, linear growth functionals in image restoration", SIAM journal on applied mathematics, vol. 66, no. 4, pp. 1383-1406, 2006. doi: 10.1137/ 050624522

[6] L. Diening, P. Nägele, and M. Růžička, "Monotone operator theory for unsteady problems in variable exponent spaces", Complex variables and elliptic equations, vol. 57, no. 11, pp. 1209-1231, 2011. doi: 10.1080/ 17476933.2011.557157

[7] L. Diening, P. Harjulehto, P. Hästö, and M. Růžička, Lebesgue and Sobolev spaces with variable exponents. Berlin: Springer, 2011.

[8] X. -L. Fan and D. Zhao, "On the spaces $\mathrm{L}^{\mathrm{p}(\mathrm{x})}(\Omega)$ and $\mathrm{W}^{\mathrm{m}, \mathrm{p}(\mathrm{x})}(\Omega)$," Journal of mathematical analysis and applications, vol. 263, no. 2, pp. 424-446, 2001. doi: 10.1006/jmaa.2000.7617

[9] Y. Q. Fu and N. Pan, "Existence of solutions for nonlinear parabolic problem with $\mathrm{p}(\mathrm{x})$-growth", Journal of mathematical analysis and applications, vol. 362, no. 2, pp. 313-326, 2010. doi: 10.1016/j.jmaa. 2009.08.038

[10] P. Harjulehto, P. Hästö, M. Koskenoja, and S. Varonen, "The dirichlet energy integral and variable exponent sobolev spaces with zero boundary values", Potential analysis, vol. 25, no. 3, pp. 205-222, 2006. doi: 10.1007/ s11118-006-9023-3

[11] O. Kovácik and J. Rákosník, “On Spaces $\mathrm{L}^{\mathrm{p}(\mathrm{x})}$ and $\mathrm{W}^{\mathrm{k}, \mathrm{p}(\mathrm{x})}$," Czechoslovak mathematical journal, vol. 41, pp. 592-618, 1991.

[12] R. Landes, "On the existence of weak solutions for quasilinear parabolic initial-boundary value problems", Proceedings of the royal society of Edinburgh: Section A mathematics, vol. 89, no. 3-4, pp. 217-237, 1981. doi: $10.1017 /$ s0308210500020242

[13] J.-L. Lions, Quelques méthodes de résolution des problèmes aux limites on lineaires. Paris: Dunod Gauthier Villars, 1969.

[14] J. -L. Lions and E. Magenes, Problèmes aux limites non homogènes et applications. Paris: Dunod Gauthier Villars, 1968.

[15] M. Růžička, Electrorheological fluids: modeling and mathematical theory. Berlin: Springer, 2000.

[16] S. G. Samko, "Density of $\mathrm{C}_{0}^{\infty}\left(\mathrm{R}^{\mathrm{N}}\right)$ in the generalized Sobolev spaces $\mathrm{W}^{\mathrm{m}, \mathrm{p}(\mathrm{x})}\left(\mathrm{R}^{\mathrm{N}}\right)^{\prime \prime}$, Doklady Akademii Nauk, vol. 369, no. 4, pp. 451-454, 1999. 
[17] J. Simon, Compact set in the space $\mathrm{L}^{\mathrm{p}}(0, \mathrm{~T}, \mathrm{~B})$, Annali di matematica pura ed applicata, vol. 146, pp. 65-96, 1987. Available: https:// bit.ly/ 3HTNuLM

[18] A. Youssfi, E. Azroul, and B. Lahmi, "Nonlinear parabolic equations with nonstandard growth", Applicable analysis, vol. 95, no. 12, pp. 2766-2778, 2015. doi: 10.1080/ 00036811.2015.1111999

[19] C. Zhang and S. Zhou, "Renormalized and entropy solutions for nonlinear parabolic equations with variable exponents and L1 data", Journal of differential equations, vol. 248, no. 6, pp. 1376-1400, 2010. doi: 10.1016/j.jde.2009.11.024

[20] V. V. Zhikov, "On Lavrentiev's phenomen", Russian Journal of Mathematical Physics, vol. 3, no. 2, pp. 249-269, 1995.

[21] V. V. Zhikov, "On the density of smooth functions in Sobolev-Orlicz spaces", Zapiski naučnyh seminarov Leningradskogo otdeleniâ ordena Lenina matematičeskogo instituta im. V.A. Steklova Akademii nauk SSSR, vol. 310, pp. 67-81, 2004. 


\section{Mustapha Ait Hammou}

Laboratory Lama,

Department of Mathematics,

Sidi Mohamed Ben Abdellah University,

Fez,

Morocco,

e-mail: mustapha.aithammou@usmba.ac.ma

orcid.org/0000-0002-3930-3469

Corresponding author

\section{Elhoussine Azroul}

Laboratory Lama,

Department of Mathematics,

Sidi Mohamed Ben Abdellah university,

Department of Mathematics,

Fez,

Morocco,

e-mail: elhoussine.azroul@usmba.ac.ma

orcid.org/0000-0002-2396-4844

and

\section{Badr Lahmi}

Laboratory LMI,

Department of Mathematics,

Moulay Ismail university,

Meknes,

Morocco,

e-mail: lahmi.badr@gmail.com

orcid.org/0000-0001-5180-4744 